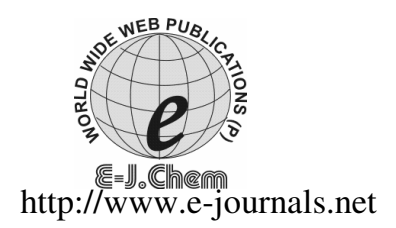

\title{
Kinetics and Mechanism of Oxidation of Glutamic Acid by $N$-Bromophthalimide in Aqueous Acidic Medium
}

\author{
N.M.I. ALHAJI" and S. SOFIYA LAWRENCE MARY \\ P.G. and Research Department of Chemistry \\ Khadir Mohideen College, Adirampattinam - 614 701, India \\ alhajinmi@yahoo.in
}

Received 20 April 2011; Accepted 25 June 2011

\begin{abstract}
The kinetics of oxidation of glutamic acid (Glu) with $N$-bromophthalimide (NBP) was studied in perchloric acid medium at $30{ }^{\circ} \mathrm{C}$ by potentiometric method. The reaction is first order each in NBP and glutamic acid and is negative fractional order in $\left[\mathrm{H}^{+}\right]$. Addition of $\mathrm{KBr}$ or the reaction product, phthalimide had no effect on the rate. Similarly variation of ionic strength of the medium did not affect the rate of the reaction. Also the rate increased with decrease in dielectric constant of the reaction medium. The thermodynamic parameters were computed from Arrhenius and Eyring plots. A suitable mechanism consistent with the kinetic results has been proposed.
\end{abstract}

Keywords: Potentiometry, $N$-Bromophthalimide, Glutamic acid, Oxidation, Mechanism

\section{Introduction}

The studies of oxidation of amino acids are of utmost interest in order to understand the metabolism of the proteins in biological systems. The amino and carboxyl functional groups present in amino acids $\mathrm{RCH}\left(\mathrm{NH}_{2}\right) \mathrm{COOH}$ is more reactive compared to the hydrocarbon $(\mathrm{R})$ moiety and hence only these functional groups undergo chemical transformation. The $N$-halo compounds interact with a wide range of functional groups as they are capable of existing as halonium cations, hypohalite species and $N$-anions in aqueous solution ${ }^{1}$. There are many reports on the kinetics of oxidation of amino acids with $\mathrm{N}$-halo compounds, such as chloramine- $\mathrm{B}^{2}$, chloramine- $\mathrm{T}^{3-5}$, bromamine- $\mathrm{T}^{6}, \quad$ bromamine- $\mathrm{B}^{7,8}, \quad N$-bromoactamide ${ }^{9}$, $N$-chloronicotinimide ${ }^{10}, N$-bromonicotinimide ${ }^{11}, N$-chlorosaccharin ${ }^{12}$ and $N$-bromophthalimide ${ }^{13}$ etc. Here we report the results of the kinetic studies of the oxidation of glutamic acid with $\mathrm{N}$-bromophthalimide in aqueous perchloric acid medium.

\section{Experimental}

$\mathrm{N}$-Bromophthalimide (Aldrich, purity 99\%) was used as received. The standard solution in distilled water was prepared afresh every week and standardized against thio. Chromatographically pure $L$-glutamic acid (SRL, India) was further assayed by acetous perchloric method $^{14}$. All other chemicals were of Analar grade. 


\section{Kinetic measurements}

The kinetic runs were carried out in aqueous perchloric acid medium. The ionic strength of the reaction medium was maintained by addition of $\mathrm{NaClO}_{4}$. The kinetics were followed potentiometrically in a manner as described earlier ${ }^{15}$. The emf of the cell was measured periodically using an Equip-Tronics potentiometer while the reaction mixture was magnetically stirred continuously. The temperature of the reaction mixture was maintained at the desired value to an accuracy of $\pm 0.1{ }^{\circ} \mathrm{C}$ by circulating thermostated water in the reaction vessel. The pseudo first-order rate constants $\left(\mathrm{k}_{\mathrm{obs}}\right)$ were calculated from the slopes of $\ln \left(\mathrm{E}_{\mathrm{t}}-\mathrm{E}_{\infty}\right)$ versus time plots $(\mathrm{r}>0.990)$ and the results were reproducible to an accuracy of $\pm 5 \%$. The second-order rate constants $\left(k_{2}\right)$ were obtained as $k_{\mathrm{obs}} /[\mathrm{Glu}]$.

\section{Stoichiometry and product analysis}

Varying ratios of $N B P$ to glutamic acid were equilibrated at $30{ }^{\circ} \mathrm{C}$ in presence of $0.20 \mathrm{M}$ $\mathrm{HClO}_{4}$ for 24 hours. Estimation of the unreacted $N B P$ established a1:2 stoichiometry.

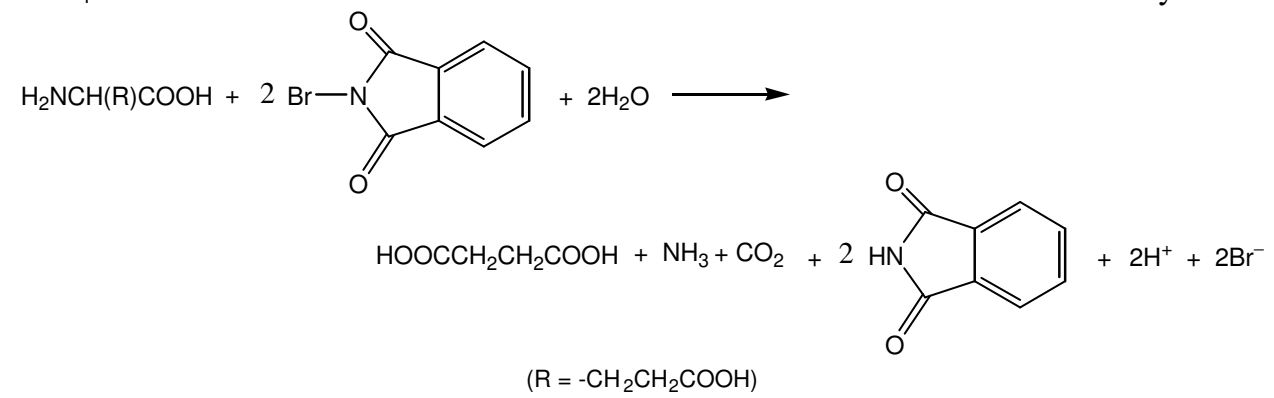

Ammonia was detected by Nessler's reagent. Succinic acid was detected by spot test ${ }^{16}$. The liberated $\mathrm{CO}_{2}$ was confirmed by lime-water test.

\section{Results and Discussion}

Kinetics of oxidation of glutamic acid by $\mathrm{N}$-bromophthalimide was investigated at several initial concentrations of the reactants in $\mathrm{HClO}_{4}$ medium under pseudo-first order conditions of $[$ substrate $] \gg[\mathrm{NBP}]$. At constant $[\mathrm{Glu}]_{\mathrm{o}},\left[\mathrm{HClO}_{4}\right],\left[\mathrm{NaClO}_{4}\right]$ and temperature, plots of $\ln \left(\mathrm{E}_{\mathrm{t}}-\mathrm{E}_{\infty}\right)$ vs. time were linear $(\mathrm{r}>0.992)$ indicating first-order dependence of rate on $[\mathrm{NBP}]_{\mathrm{o}}$. Furthermore, the rate constants did not change with change in $[\mathrm{NBP}]_{\mathrm{o}}$ (Table 1), confirming first-order dependence on $[\mathrm{NBP}]_{\mathrm{o}}$. Also, the rate data in Table 1 point out that $k_{o b s}$ value increases linearly in a first-order fashion with increase in the initial concentration of Glu. A plot of $\log k_{o b s} v s . \log [\mathrm{Glu}]_{\mathrm{o}}$ was linear $(\mathrm{r}=0.991)$ with slope value almost equal to one. Also the plot of $k_{o b s} v s$. [Glu] passed through the origin (Figure $1 ; \mathrm{r}=0.992$ ), establishing the first order dependence of rate on $[\mathrm{Glu}]_{\mathrm{o}}$. The rate decreased with increase in $\left[\mathrm{HClO}_{4}\right]\left(\right.$ Table 1) and the plot of $\log k_{o b s} v s . \log \left[\mathrm{H}^{+}\right]_{\mathrm{o}}$ was found to be linear $(\mathrm{r}=0.994)$ showing a negative first-order dependence on $\left[\mathrm{H}^{+}\right]_{\mathrm{o}}$. Further, the plot of $k_{o b s} v s .1 /\left[\mathrm{H}^{+}\right]_{\mathrm{o}}$ was linear and passed through the origin (Figure 2), indicating that the oxidation occurred only through the acid dependent path under these conditions.

The rate of the reaction is not significantly affected by the change in the ionic strength of the medium (Table 2) brought about by the addition of sodium perchlorate, pointing out the participation of a neutral species as a reactant in the rate-determining step. Addition of phthalimide caused no effect on the rate of reaction (Table 2) suggesting that the step in which phthalimide is formed as one of the products is not reversible. 
Table 1. Pseudo first-order and second-order rate constants for the oxidation of glutamic acid by NBP in aqueous perchloric acid at $303 \mathrm{~K}^{\mathrm{a}, \mathrm{b}}$

\begin{tabular}{ccccc}
\hline $10^{3}[\mathrm{Glu}]_{\mathrm{o}}, \mathrm{M}$ & $10^{4}[\mathrm{NBP}]_{\mathrm{o}}, \mathrm{M}$ & $10^{2}\left[\mathrm{H}^{+}\right]_{\mathrm{o}}, \mathrm{M}$ & $10^{4} k_{\mathrm{obs}}{ }^{\mathrm{c}}, \mathrm{s}^{-1}$ & $10^{2} k_{2}{ }^{\mathrm{d}}, \mathrm{M}^{-1} \mathrm{~s}^{-1}$ \\
\hline 2.0 & 2.0 & 4.0 & $2.25 \pm 0.25$ & $11.2 \pm 1.3$ \\
4.0 & 2.0 & 4.0 & $4.12 \pm 0.39$ & $10.3 \pm 1.0$ \\
8.0 & 2.0 & 4.0 & $8.05 \pm 0.71$ & $10.6 \pm 0.9$ \\
12.0 & 2.0 & 4.0 & $12.9 \pm 1.14$ & $10.7 \pm 1.0$ \\
20.0 & 2.0 & 4.0 & $21.9 \pm 1.95$ & $10.9 \pm 1.0$ \\
4.0 & 0.5 & 0.4 & $4.29 \pm 0.38$ & $10.7 \pm 1.0$ \\
4.0 & 1.0 & 4.0 & $4.21 \pm 0.39$ & $10.5 \pm 1.0$ \\
4.0 & 3.0 & 4.0 & $4.18 \pm 0.36$ & $10.5 \pm 0.91$ \\
4.0 & 2.0 & 2.0 & $8.36 \pm 0.81$ & $20.9 \pm 2.0$ \\
4.0 & 2.0 & 8.0 & $2.16 \pm 0.20$ & $5.39 \pm 0.50$ \\
4.0 & 2.0 & 12.0 & $1.11 \pm 0.10$ & $2.79 \pm 0.24$ \\
4.0 & 2.0 & 20.0 & $0.82 \pm 0.07$ & $2.05 \pm 0.19$ \\
\hline
\end{tabular}

${ }^{a}$ As determined by a potentiometric technique following the disappearance of NBP; the error quoted in $k$ values is the $95 \%$ confidence limit of 'Student t test ${ }^{, 17} .{ }^{b}$ General conditions: $[I]=0.75 \mathrm{M} ;{ }^{c}$ Estimated from pseudo first-order plots over $60 \%$ reaction. ${ }^{d}$ Individual $k_{2}$ values estimated as $k_{\text {obs }} /[G l u]_{o}$.

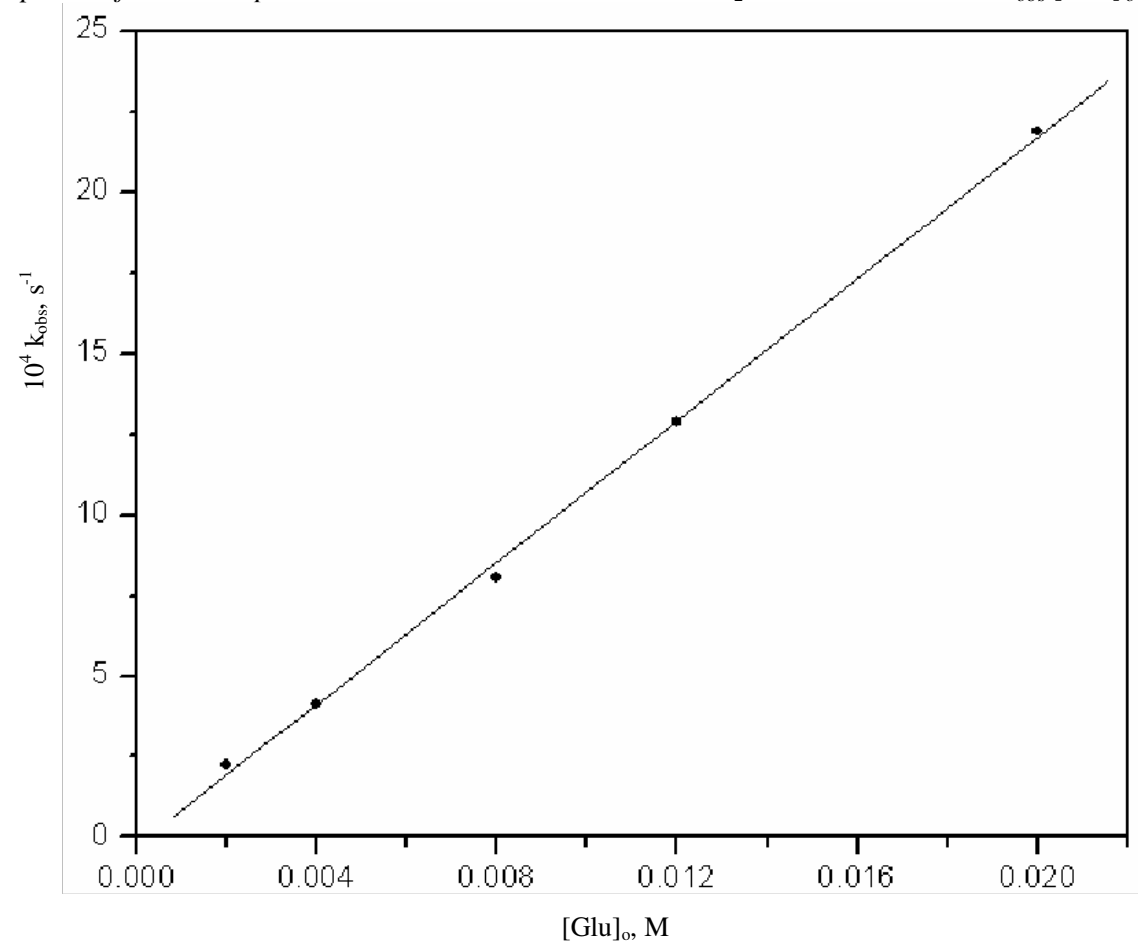

Figure 1. Direct plot of $k_{\text {obs }}$ versus [amino acid] for the oxidation of glutamic acid with NBP 


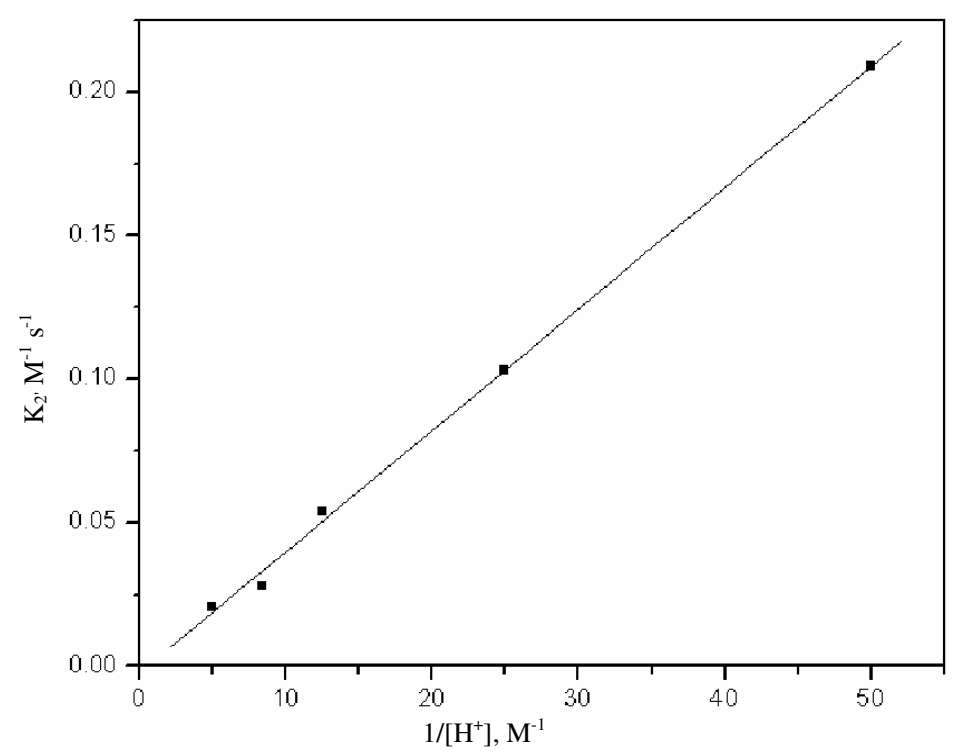

Figure 2. Plot of $k_{2}$ vs. $1 /\left[\mathrm{H}^{+}\right]$for the oxidation of glutamic acid with NBP

Table 2. Influence of ionic strength and phthalimide (NHP) on reaction rate for the oxidation of glutamic acid with NBP at $303 \mathrm{~K}^{\mathrm{a}}$

\begin{tabular}{cccc}
\hline$[\mathrm{I}], \mathrm{M}$ & $10^{4} k_{\text {obs }}, \mathrm{s}^{-1}$ & $10^{4}[\mathrm{NHP}], \mathrm{M}$ & $10^{4} k_{\text {obs }}, \mathrm{s}^{-1}$ \\
\hline 0.30 & $4.08 \pm 0.41$ & 0 & $4.12 \pm 0.39$ \\
0.50 & $4.07 \pm 0.39$ & 1.0 & $4.06 \pm 0.39$ \\
0.75 & $4.12 \pm 0.39$ & 3.0 & $4.18 \pm 0.41$ \\
1.00 & $4.18 \pm 0.40$ & & \\
\hline
\end{tabular}

${ }^{a}$ General conditions: $[\mathrm{NBP}]=0.0002 \mathrm{M} ;[\mathrm{Glu}]=0.004 \mathrm{M} ;\left[\mathrm{H}^{+}\right]=0.04 \mathrm{M} ;[\mathrm{I}]=0.75 \mathrm{M}$ unless otherwise stated

The involvement of free-radical intermediates during the reaction can be excluded as the rate constant is not affected by the addition of acrylonitrile (Table 3). The added $\mathrm{KBr}$ has no effect on the rate of oxidation (Table 3), establishing that the course of the oxidation does not involve $\mathrm{Br}^{+}$ion or $\mathrm{Br}_{2}$ as active species. Addition of acetonitrile to the reaction mixture increased the rate (Table 3) and a plot of $\log k_{o b s} v s .1 / \mathrm{D}$ is linear with a positive slope.

Table 3. Influence of added acrylonitrile (AN), $\mathrm{KBr}$ and solvent polarity on reaction rate for the oxidation of glutamic acid with NBP at $303 \mathrm{~K}^{\mathrm{a}}$

\begin{tabular}{cccccc}
\hline$[\mathrm{AN}], \mathrm{M}$ & $10^{4} k_{\text {obs }}, \mathrm{s}^{-1}$ & {$[\mathrm{KBr}], \mathrm{M}$} & $10^{4} k_{\text {obs }}, \mathrm{s}^{-1}$ & $\% \mathrm{CH}_{3} \mathrm{CN}(\mathrm{v} / \mathrm{v})^{\mathrm{b}}$ & $10^{4} k_{\text {obs }}, \mathrm{s}^{-1}$ \\
\hline 0 & $4.12 \pm 0.39$ & 0 & $4.12 \pm 0.39$ & 0 & $4.12 \pm 0.39$ \\
0.003 & $4.16 \pm 0.40$ & 0.001 & $4.09 \pm 0.39$ & 10 & $5.28 \pm 0.51$ \\
0.006 & $4.18 \pm 0.40$ & 0.002 & $4.08 \pm 0.39$ & 20 & $7.36 \pm 0.75$ \\
& & 0.004 & $4.09 \pm 0.40$ & 40 & $10.1 \pm 0.98$ \\
\hline
\end{tabular}

${ }^{a}$ General conditions: $[\mathrm{NBP}]=0.0004 \mathrm{M} ;[\mathrm{Glu}]=0.004 \mathrm{M} ;\left[\mathrm{H}^{+}\right]=0.04 \mathrm{M} ;[\mathrm{I}]=0.75 \mathrm{M}$

The reaction was studied at three other temperatures $(298,308$ and $318 \mathrm{~K})$ keeping other experimental conditions constant. From the arrehenius and eyring plots, the thermodynamic parameters for the oxidation of glutamic acid were found to be $\mathrm{E}_{\mathrm{a}}=48.69$ $\mathrm{kJ} / \mathrm{mol}, \Delta H^{\neq}=44.69 \mathrm{~kJ} / \mathrm{mol}, \Delta G^{\neq}=79.12 \mathrm{~kJ} / \mathrm{mol}$ and $\Delta S^{\neq}=114.84 \mathrm{JK}^{1} \mathrm{~mol}^{1}$. 


\section{Mechanism}

The possible oxidation species in acidified NBP solution are $\mathrm{NBP}, \mathrm{NBPH}^{+}, \mathrm{HOBr}$ and $\mathrm{H}_{2} \mathrm{OBr}^{+}$. In the present study the involvement of $\mathrm{NBPH}^{+}$can be ruled out on the basis that the reaction shows a negative dependence on $\left[\mathrm{H}^{+}\right]$. Molecular bromine or bromonium ion the reactive species may not be the reactive species here because the added $\mathrm{Br}^{-}$has no effect on the rate of the reaction in present study. Another possibility of the $\mathrm{HOBr}$ or $\mathrm{H}_{2} \mathrm{OBr}^{+}$being the reactive species can be excluded on the observation that the reaction rate is not affected by the addition of phthalimide. Therefore the only choice left is to assume NBP as the oxidizing species in the present study. Variation of the ionic strength of the medium does not alter the rate indicating that no non-ionic species are involved in the rate determining step. The dielectric effect is found to be positive and hence it can be inferred that the transition state formed is less polar and there is charge disposal under these conditions. The amino acid $\mathrm{S}_{\mathrm{o}}\left({ }^{+} \mathrm{NH}_{3} \mathrm{CH}(\mathrm{R}) \mathrm{COO}^{-}\right)$under the strongly acidic condition as in the present study exits as a cation $\mathrm{SH}^{+}\left({ }^{+} \mathrm{NH}_{3} \mathrm{CH}(\mathrm{R}) \mathrm{COOH}\right)$. The negative first-order dependence of reaction rate on $\left[\mathrm{H}^{+}\right]$indicates that the amino acid takes part in the reaction in its zwitter ionic form $\mathrm{S}_{\mathrm{o}}$. Based on these findings, the following mechanism has been proposed for the oxidation of glutamic acid by NBP (Scheme1).

$$
\stackrel{\oplus}{\stackrel{\oplus}{\mathrm{NCH}}(\mathrm{R}) \mathrm{COOH} \stackrel{\mathrm{K}_{1}}{\rightleftharpoons} \stackrel{\oplus}{\rightleftharpoons} \mathrm{H}_{3} \mathrm{NCH}(\mathrm{R}) \mathrm{COO}}+\stackrel{\ominus}{ }+\mathrm{H}^{+}
$$

$$
\mathrm{R}=-\mathrm{CH}_{2} \mathrm{CH}_{2} \mathrm{COOH}
$$

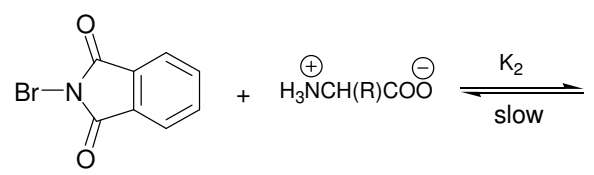<smiles>[R]C([NH3+])C(=O)OCc1ccccc1C</smiles>

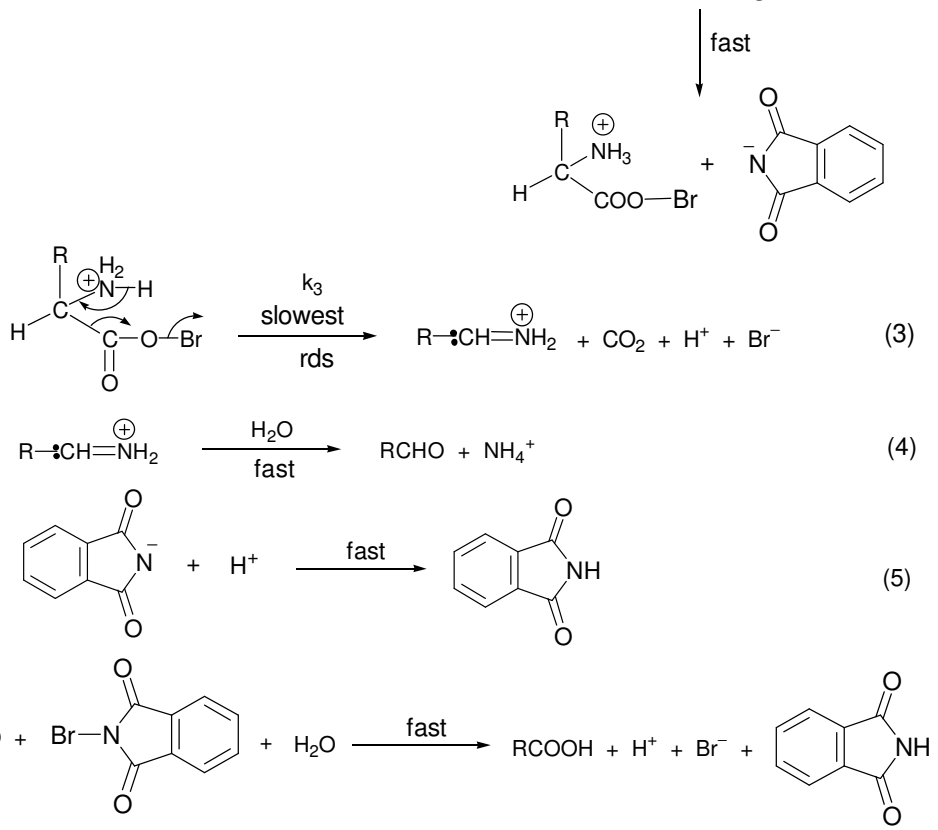

Scheme 1 
and the rate law is derived as

$$
-\frac{d[N B P]}{d t}=\frac{K_{1} K_{2} k_{3}[N B P]_{0}\left[S H^{+}\right]}{\left[H^{\dagger}\right]}
$$

The proposed mechanism is also supported by the moderate value of energy of activation and other thermodynamic parameters. The large negative $\Delta S^{\neq}$indicates the formation of an arranged complex in the rate determining step.

\section{Conclusion}

The NBP oxidation of glutamic acid follows a $S_{N} 2$ type mechanism, in which NBP itself is the oxidizing species. This mechanism is supported by the experimental data such as the reaction stoichiometry, the oxidation products and the activation parameters.

\section{Acknowledgment}

The authors thank the college management for providing the necessary facilities.

\section{References}

1. Cambell M M and Johnson G, Chem Rev., 1978, 78, 65.

2. Mahadevappa D S, Sayeed Ahamed M, Made Gowda N M and Thimme Gowda B, Int J Chem Kinet., 1983, 15, 775.

3. Mahadevappa D S, Rangappa K S, Made Gowda N M and Thimme Gowda B, Int J Chem Kinet., 1982, 14, 1183-1197.

4. Kutti Rani S, Eswaramoorthy D, Mohamed Bilal T and Palanichamy M, Appl Catal A: General, 2009, 369(1-2), 1-7.

5. Katre Y R, Solanki S K, Sangeetha P and Joshi G K, Asian J Chem., 2005, 17, 423.

6. Mahadevappa D S, Puttaswamy and Made Gowda N M, Proc Indian Acad Sci., (Chem Sci), 1988, 100(4), 261.

7. Puttaswamy and Nirmala Vaz, Proc Indian Acad Sci (Chem Sci.,) 2001, 113, 325-332.

8. Puttasamy M and Nirmala Vaz N, J Indian Chem Soc., 2004, 81, 479.

9. Bisnoi M L and Banerji K K, Tetrahedron, 1985, 41(24), 6047-6050.

10. Vivekanandan K and Nambi K, J Indian Chem Soc., 1999, 76, 198-201.

11. Pushphalatha L and Vivekanandan K, J Indian Chem Soc., 2009, 86(5), 475-480.

12. Mohamed Farook N A, Seyed Dameem G A, Murugesan A and Kanagaraj M, E-J Chem., 2004, 1(2), 132-136.

13. Singh A K, Jain B, Negi R, Katre Y, Singh S P and Sharma V K, Synth React Inorg, Metal-Org Nano-Metal Chem., 2010, 40, 71-77.

14. Vogel A I, Quantitative Organic Analysis, London, Langman Green, 1958, 708.

15. Mohan Das C and Indrasenan P, Indian J Chem., 1987, 26A, 55.

16. Feigl F, Spot Tests in Organic Analysis, (Amsterdam; Elsevier), 1958, 120.

17. Srinivasan C, Rajagopal S and Chellamani A, J Chem Soc Perkin Trans 2, 1990, 1839. 


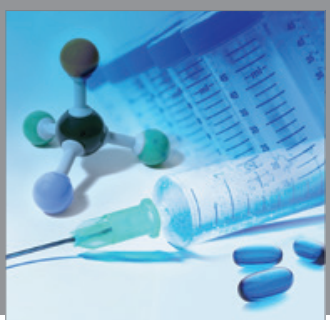

International Journal of

Medicinal Chemistry

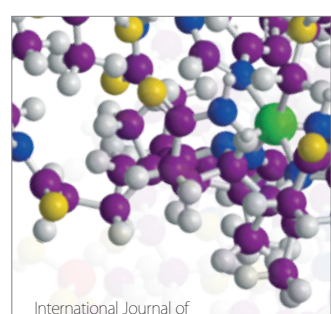

Carbohydrate Chemistry

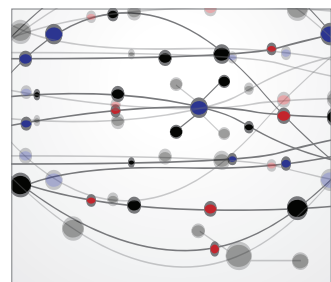

The Scientific World Journal
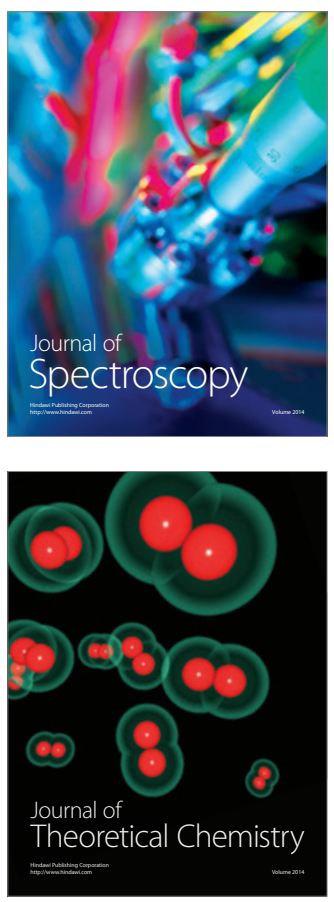
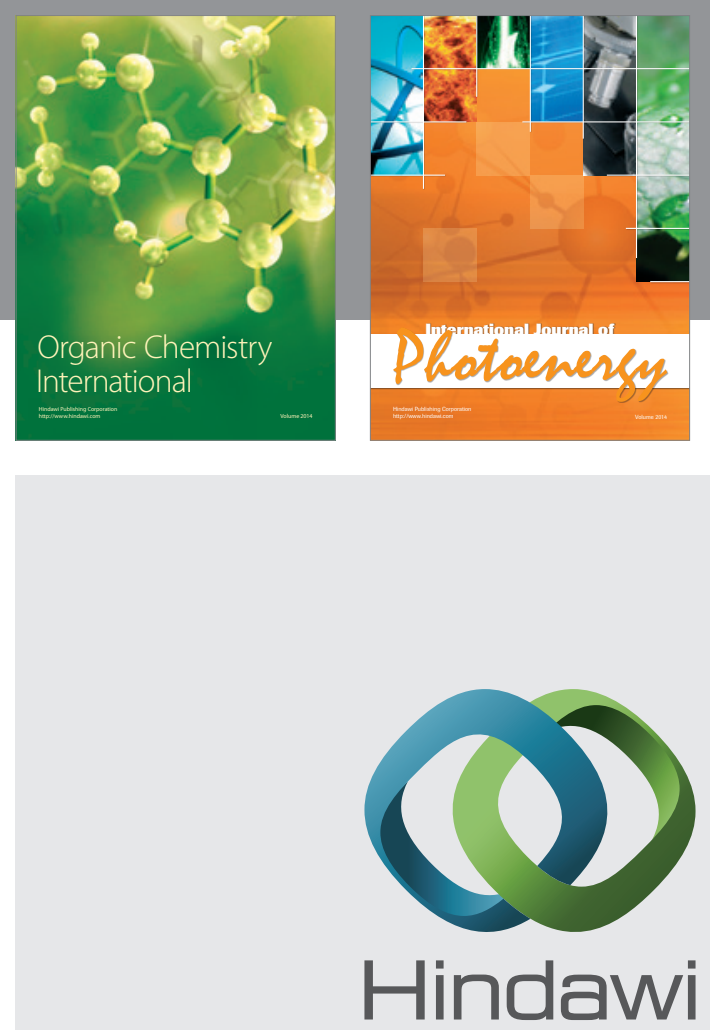

Submit your manuscripts at

http://www.hindawi.com
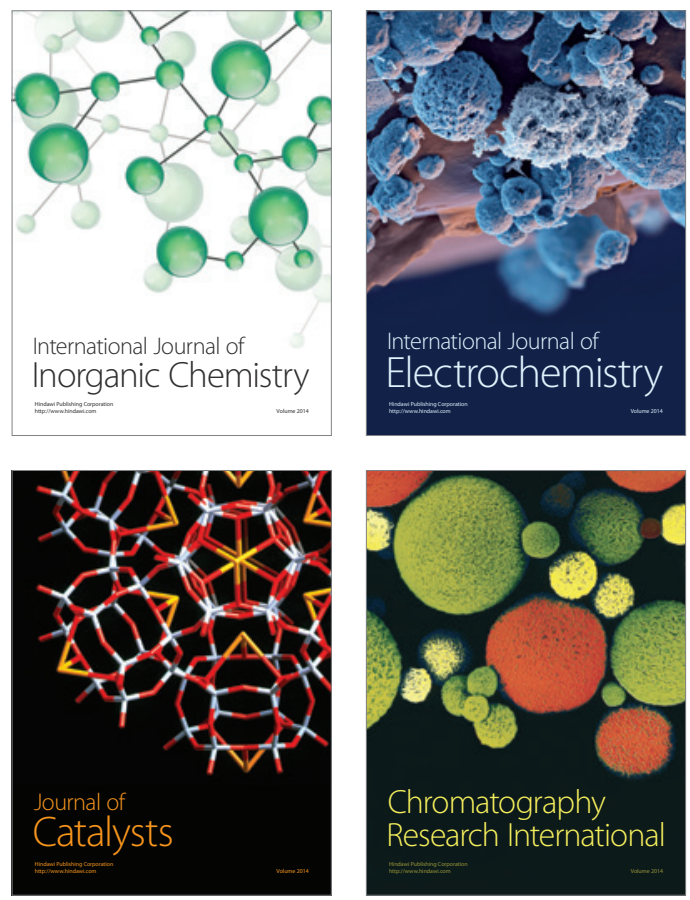
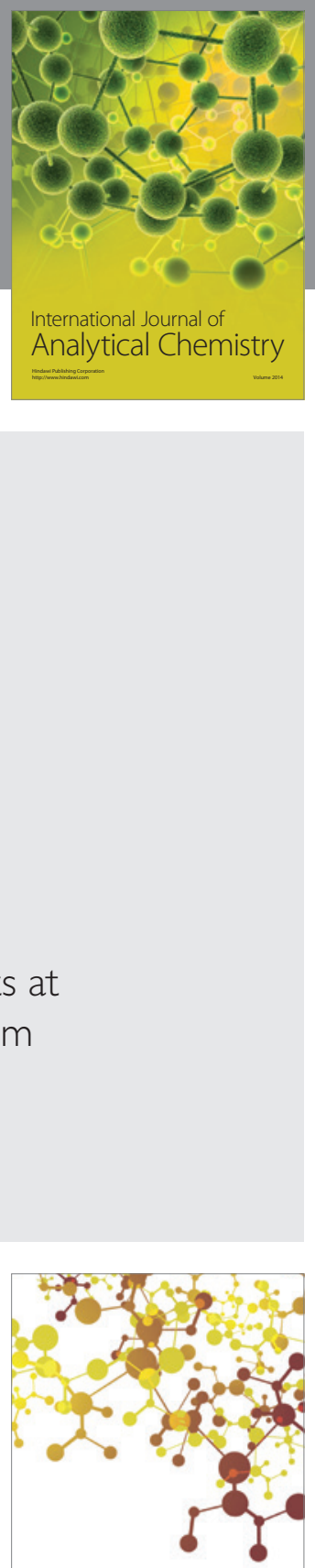

Journal of

Applied Chemistry
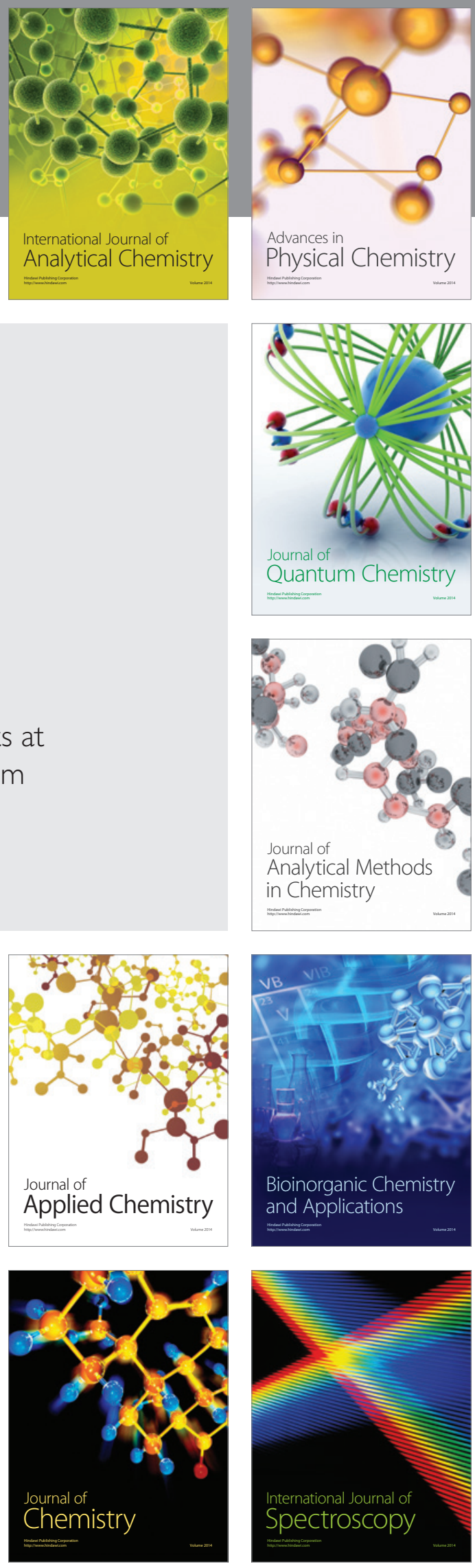